
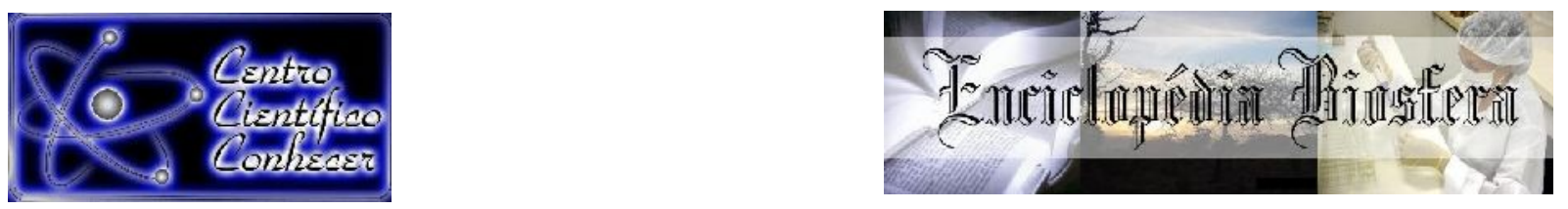

\title{
COMUNICAÇÃO EMOCIONAL ENTRE O HOMEM E O ANIMAL NÃO - HUMANO
}

1 Jéssica Ataide Batista Nigro; ${ }^{2}$ Ana Cláudia Balda; ${ }^{3}$ Charlotte Cesty Borda Saenz

${ }^{1}$ Discente do curso de graduação em Ciências Biológicas do Centro Universitário das

Faculdades Metropolitanas Unidas - FMU.

E-mail: jeeh.ss@hotmail.com

2 Coordenadora do curso de Medicina Veterinária do Centro Universitário das

Faculdades Metropolitanas Unidas - FMU

3 Docente do curso de graduação em Ciências Biológicas do Centro Universitário das

Faculdades Metropolitanas Unidas - FMU

Recebido em: 15/11/2020 - Aprovado em: 15/12/2020 - Publicado em: 30/12/2020

DOI: 10.18677/EnciBio_2020D45

\begin{abstract}
RESUMO
"Comunidades híbridas" é o termo utilizado para determinar a relação estabelecida entre humanos e outras espécies, conforme definições filosóficas, clássicas e contemporâneas, excluem ou incluem os animais não humanos. Constantemente, seres humanos relatam que observaram comportamentos de outros animais que demonstram expressão do estado de amor, empatia, euforia e sentimentos subjetivos que, anteriormente, estavam associados apenas aos humanos, mas já possíveis de serem identificados em experimentos científicos. Com este intuito, o objetivo deste trabalho foi fazer uma revisão bibliográfica sobre a comunicação emocional entre os animais humanos e não-humanos. Diversos estudos identificaram que a relação entre humanos e animais, promove a liberação de hormônios como a oxitocina e vasopressina, interferon e endorfina, consequências de demonstração de interação social e empatia da parte dos animais, como o exemplo de cães e gatos utilizados em terapia assistida e a relação de golfinhos com crianças, autistas e pacientes com deficiência mental. Já foram relatadas que experiências desagradáveis podem ocasionar redução do telômero, o que pode indicar dano celular associado ao envelhecimento cronológico e redução na expectativa de vida do animal. A partir disto, foi analisada a complexidade do cérebro animal, identificando-os como seres sencientes e dotados de consciência emocional e sentimental, utilizando explicações a nível neural, genética, hormonal e comportamental. Finalmente, a partir deste estudo é possível entrar em quesitos éticos de como os seres humanos tratam e interagem com os animais, o que pode ser feito para aumentar o seu bem-estar e como os seres humanos podem melhorar a interação com os seres de outras espécies.
\end{abstract}

PALAVRAS-CHAVE: emoções, empatia, etologia cognitiva, luto, senciência. 


\title{
EMOTIONAL COMMUNICATION BETWEEN HUMAN AND ANIMALS NO HUMAN
}

\begin{abstract}
"Hybrid communities" is the term used to determine the applicable relationship between humans and other species, according to philosophical, classic and contemporary definitions, which exclude or include non-human animals. Constantly, human beings report that they have observed behavior of other animals that demonstrate expression of the feeling of love, empathy, euphoria and subjective feelings that previously were associated only with humans, but already possible to be identified in scientific experiments. With this aim, the objective of this work was to make a bibliographic review on the emotional communication between human and non-human animals. Several studies have identified that the relationship between humans and animals, promoting the release of hormones such as oxytocin and vasopressin, Interferon and Endorphin, consequences of demonstrating social interaction and empathy on the part of animals, such as the example of dogs and cats used in assisted therapy and the relationship of dolphins with children, autists and patients with mental disabilities. It has been reported that unpleasant experiences can cause telomere reduction, which can indicate cellular damage associated with chronological aging and reduced animal life expectancy. From this, the complexity of the brain was analyzed, identifying them as sentient beings and endowed with emotional and sentimental awareness, using explanations at the neural, genetic, hormonal and behavioral levels. Finally, from this study it is possible to enter into ethical questions of how we treat the animals we interact with, what we can do to increase their well-being and how we can become better humans in interacting with beings of other species.
\end{abstract}

KEYWORDS: cognitive ethology, emotion, empathy, mourning, sentience.

\section{INTRODUÇÃO}

Constantemente, vídeos amadores ou documentários de grandes canais mostram diversas manifestações de comportamento cognitivo e social de animais demonstrando comportamentos sociais como golfinhos respondendo à comandos realizados por treinadores, elefantes movendo esforços para salvar um filhote que ficou encurralado em valões, cachorros e gatos fazendo algo considerado fofo para chamar a atenção de seus tutores. Além da percepção popular, uma pesquisa de influência de convivência, realizada por Raísa Duquia Giumelli e Marciane Cleuri Pereira Santos (2016), relata que quem tem a companhia de um animal doméstico descreve um estado de amor e a percepção de carinho sobre ser recebido por seu cão animado com movimentos caudais ou o gato vocalizando e ronronando como sinal de retribuição do sentimento de amor ou necessidade de atenção. Outras pessoas relatam que a presença deles ajuda a trazer conforto em dias em que estão mais tristes ou mais felizes (GIUMELLI; SANTOS, 2016).

Além disso, vem aumentando a quantidade de pessoas que consideram os animais não humanos como membros de suas famílias, aumentando a inserção desses animais no núcleo familiar (INSTITUTO PET BRASIL, 2019) e reduzindo a prole humana. Esse dinamismo enquadra-se no conceito da família multiespécie (ou pluriespécie, considerando o modelo eudemonista), tendo em seu arranjo social 
humanos e não-humanos com o objetivo de alcançar a felicidade com vínculos afetivos e não necessariamente biológicos (NAVES; VARELLA, 2018; CABRAL; SILVA, 2019).

Para elucidar o modo como o homem e os animais não-humanos comunicam-se, é preciso um destaque resumido de similaridades que ocorrem nas espécies. Segundo Damásio (2015), as emoções desempenham um papel fundamental no organismo formando um conjunto complexo de reações químicas e neurais, afetando inúmeros circuitos cerebrais. São processos biológicos que ocorrem em um grupo restrito de regiões subcorticais, e dependem de mecanismos cerebrais estabelecidos de modo inato, mas alguns fatores como aprendizado e cultura podem influenciar nas expressões das emoções e nos seus significados. As emoções podem ser acionadas de modo automático ou não, conscientemente ou não (DAMÁSIO, 2015; TELES, 2020).

As emoções podem se manifestar de modo primário tanto em humanos quanto em animais, como alegria, tristeza, medo, raiva, surpresa ou repugnância e evoluir conforme o processamento da experiência que o indivíduo está tendo. Ela pode ser primária, secundária ou social, emoção de fundo e processada (DAMÁSIO, 2012 citado por TELES, 2020).

Para explicar biologicamente, as emoções ocorrem nas regiões subcorticais do cérebro, da amígdala e do córtex pré-frontal ventromedial, criando reações bioquímicas no corpo e alterando assim o estado físico. As emoções são codificadas nos genes e funcionam em todos os seres humanos de forma similar. Emoções ajudam nas relações sociais e de sobrevivência mediante alegria, medo, preocupação, amor, entre outros. Nas amígdalas, há liberação de neurotransmissores essenciais para a consolidação da memória que podem ser muito mais fortes e duradouras (PORTO, 2017).

Já os sentimentos são experiências subjetivas do estado de vida que ocorre em todo organismo que possui uma mente e um ponto de vista consciente. Eles são originados nas emoções, mas não necessariamente provem delas. Atuam no modelo de como a mente vai processar as tomadas de decisão para o que acontece no entorno. Também podem manifestar-se de diversos níveis. Tanto as emoções quanto os sentimentos preparam o organismo para diversas respostas, como contração ou relaxamento de músculos, alteração de mucosas, fluxo sanguíneo, entre outras reações homeostáticas (DAMÁSIO, 2015; DAMÁSIO, 2018; DAMÁSIO, 2012 citado por TELES, 2020).

Em 1872, Charles Darwin publicou o livro "As expressões das emoções no homem e nos animais" e nesta época teorizava que os "animais inferiores" (não - humanos) também sentiam medo, raiva, ciúme, manifestados por meio de expressões. Sendo essas expressões oriundas do processo de adaptação do indivíduo ao meio e, consequentemente, herdadas de gerações anteriores, como hábitos de caça, espantar predadores como o guizo da cascavel, o sono quando o cachorro roda três vezes para deitar no tapete desejado semelhante como se estivesse afofando a grama, prazer em se alimentar visto em gatos quando pressionam as tetas das mães hábito o qual, apresentam depois na fase adulta "amassando" lençóis (DARWIN, 2009) [1872].

Os seres humanos usam as expressões para demonstrar as emoções, já em animais experimentos com chimpanzés, em relação à expressão física das emoções, há trabalhos que observam a existência de vínculos entre lateralidade nas expressões 
faciais e expressões de emoções realizadas por eles (LYDDY, 2002; RAPCHAN; NEVES 2017).

Até meados do século passado, as questões de bem-estar e direito dos animais ainda eram algo muito distante da realidade dos seres humanos. Os animais nãohumanos eram vistos como seres assessórios no cotidiano dos seres humanos e serviam única e exclusivamente para servir, como puxadores de carga, como alimento, testes laboratoriais, entretenimento em zoológicos e aquários, entre outros (BAPSTISTELLA; ABONIZIO, 2017).

Foi possível analisar, ao longo dos anos, que os temas bem-estar animal e direito dos animais vêm se tornando fortes e luta daqueles que entendem que os animais precisam, sim, de voz e proteção, com um discurso de que não existem tantas diferenças entre os seres humanos e os demais animais como era imaginado. Para Thomas (2010), a justificativa de como os seres humanos se comportavam desta forma em relação aos demais animais dá-se porque existem diferenças entre a fala, beleza, fisiologia, inteligência, entre outros. Essa análise sugeria que os animais eram limitados intelectualmente e isto também justificava o comportamento predatório indiferente às questões de bem-estar animal (THOMAS, 2010; BAPSTISTELLA; ABONIZIO, 2016; BAPSTISTELLA; ABONIZIO, 2017).

A partir disto, mesmo sem uma linguagem compatível com a humana, algumas pessoas enxergaram que era necessário dar voz aos demais animais. O que culminou no início de ONG's e instituições voltadas para a defesa de animais domésticos e silvestres (THOMAS, 2010; BAPSTISTELLA; ABONIZIO, 2016; BAPSTISTELLA; ABONIZIO, 2017). Inclusive, muitos estudos e protocolos vêm sendo criados para que os animais sofram cada dia menos com os impactos causados pelas ações antrópicas. Para isso, o paradigma das Cinco provisões/objetivos - Cinco liberdades - de bemestar animal, promove que o animal não-humano prospere ao invés de somente sobreviver, tendo como garantia a alimentação, lazer, diversão, local para realizar as necessidades fisiológicas, espaço para recreação, abrigo, acesso à tratamentos de saúde, menor risco de estresse e condições de experiências positivas em relação à saúde mental. Desta forma, os responsáveis pelos animais, sendo estes domésticos ou de cativeiro, precisam seguir um conjunto de metas de bem-estar (MELLOR, 2016).

Esses protocolos também são abordados quando os estudos são realizados com animais de experimentação. As questões de bem-estar animal incluem impactos negativos, ligados a experimentos que causem dor, medo, fome e demais necessidades fisiológicas, também aos que inferem manuseio e transporte, infecções e lesões físicas. Já os impactos positivos, como métodos de criação, disposição à saúde ou outros que melhorem o bem-estar. Essa linha aponta para uma experiência cumulativa, incluindo a soma de eventos positivos e negativos que impactam na vida e bem-estar do animal (PICKARD, 2013; BATESON, 2015).

Essa premissa também vale para os animais silvestres, que a cada dia vêm perdendo mais seu habitat devido à exploração das áreas naturais pelos seres humanos. É importante entender que os seres humanos possuem responsabilidade sobre o que acontece com as outras espécies e o meio ambiente, impactando no estilo de vida e bem-estar deles. Ações antrópicas incorretas e desenfreadas causam 
perturbação de habitat e interferem na probabilidade de sobrevivência das demais espécies, já que muitas estão em risco de extinção (CAPUCCHIO et al., 2019).

É possível entrar em um campo biomolecular para explicar os impactos causados pelo não seguimento do bem-estar animal, aproveitando a tese de Melissa Bateson (2015), que abordou "a idade biológica de um animal poderia ser usada para determinar sua experiência cumulativa: animais que são biologicamente velhos para sua idade cronológica tiveram vidas relativamente desagradáveis em comparação com animais que são jovens para sua idade cronológica".

Melissa Bateson (2015) ainda relatou que em seu ensaio explorou que "as evidências de que o dano celular associado ao envelhecimento pode produzir uma medida objetiva de experiência cumulativa que pode ser útil em um contexto de bemestar animal". Esta autora explicou que existe a evidência de que o comprimento de um telômero (TL) é um biomarcador que liga o estresse ao envelhecimento prematuro e argumentou que o TA é causa de uma 'cicatriz indelével', fazendo referência aos estudos de Selye, 1956" (BATESON, 2015). Partindo do pressuposto que os níveis de experiências cumulativas podem impactar, biologicamente, no tamanho do telômero, contribuindo para mais ou menos tempo de vida do animal em sua idade cronológica (DEAN; MORGAN, 1988; BATESON, 2015).

Portanto, por meio da teoria de Bateson (2015), é sugerido que os animais que sofrem mais estresses com impactos negativos, quando não são seguidos os protocolos das Cinco Liberdades, principalmente, estão fadados a terem a expectativa de vida reduzida. É o que ocorre com determinados tipos de animais silvestres sendo criados em cativeiro, que foram capturados sem possuir, previamente, problemas adaptativos no habitat natural ao contrário dos animais domésticos que tendem a ter a expectativa de vida maior, pois além de terem sofrido evoluções adaptativas ao convívio com seres humanos, os tutores tendem a garantir que o programa de bemestar seja praticado.

Por meio dos experimentos citados e por experiências observadas e extraídas tanto de pesquisas acadêmicas como de observações cotidianas pelo convívio de tutores de animais domésticos, tratadores de animais em cativeiro ou pesquisadores de vida livre, este estudo teve o objetivo de revisar os conceitos relacionados à etologia comportamental para traçar novas perspectivas sobre como os animais compartilham de emoções e sentimentos similares aos dos humanos, como funciona a comunicação emocional entre os animais humanos e não-humanos e como isso pode ajudar a preservar espécies diante de diversas situações de maus tratos.

\section{ASSOCIAÇÕES COGNITIVAS ENTRE HOMEM E ANIMAL NÃO-HUMANO}

A relação estabelecida entre humanos e outras espécies foi chamada de "comunidades híbridas", pelo filósofo e etólogo Dominique Lestel (2004). Em seu estudo, foram abordados temas relacionados à filosofia, como a amizade, por exemplo, para verificar se as definições filosóficas, clássicas e contemporâneas, associações em que se partilham não somente interesses, mas também emoções e vínculos, envolve concepções como "indivíduos animais" e "pessoas animais" (LESTEL, 2004 citado por RAPCHAN; NEVES, 2017). 
Quando os animais não-humanos são estudados exclusivamente, é utilizada a Etologia Cognitiva, que é baseada em um estudo comparativo, evolutivo e ecológico da mente dos animais não-humanos, tendo como linha de pesquisa o modo como eles pensam e sentem, suas emoções, crenças, raciocínio, processamento de informações, consciência e autoconsiciência (BEKOFF, 2010). Para entender as relações interespécies entre humanos x não-humanos, é utilizada a Antrozoologia, que busca a compreensão social e cultural destes relacionamentos de modo a tentar entender como esses cruzamentos afetam todas as vidas envolvidas (DEMELLO, 2012 citado por GARMENDIA, 2015; BAPSTISTELLA; ABONIZIO, 2017).

O sistema nervoso de todos os vertebrados, sobretudo o de mamíferos e pássaros, é bastante parecido. Ao contrário do córtex cerebral, que só se desenvolveu plenamente depois que os ancestrais se diferenciaram dos outros mamíferos, o sistema nervoso básico evoluiu em ancestrais mais distantes, comuns aos seres humanos e aos outros animais não-humanos "superiores". O córtex cerebral é parte do cérebro associada às funções do pensamento e não aos sentimentos e emoções (SINGER, 1993 citado por TONETTO, 2004).

A parte do cérebro associada às emoções e aos sentimentos, o diencéfalo, é bem desenvolvida em muitas espécies animais, particularmente nos mamíferos e pássaros. Por meio dessas semelhanças anatômicas, os cientistas têm observado que os animais respondem fisiologicamente à dor física e psíquica (medo, ansiedade, depressão, estresse) da mesma maneira que os humanos o fazem. Por isso, quando sentem alguma dor, os animais se comportam de um jeito muito parecido com o dos humanos e o seu comportamento é suficiente para justificar a convicção de que eles sentem dor e, portanto, são conscientes (SINGER, 1993 citado por TONETTO, 2004; BEKOFF, 2010).

Para elucidar, é comum na comunidade científica, realizar experimentos voltados para esse tipo de trabalho. De Waal, mostrou em sua palestra no Ted Talks em 2011, que "a reciprocidade e empatia são pilares da moralidade, abrangendo cultura, linguagem, consciência, memória cognitiva, moral, senso de justiça, entre outros e que essas, já não são mais características e comportamento exclusivos de serem humanos" (DE WALL, 2011; RAPCHAN; NEVES, 2017). Este autor ainda relatou um experimento de 1937, que estimulou chimpanzés a associarem que a cooperação e parceria trariam o benefício de receber o alimento desejado.

O experimento gerau cooperação e reciprocidade, pois mesmo quando um dos chimpanzés já estava alimentado, foi induzido a ajudar o seu colega e, provavelmente, teria uma troca de favores. Os chimpanzés associaram que precisavam se ajudar para que recebessem o alimento. No relato sobre o estudo, eles tinham que escolher entre duas cores, verde e vermelho, para receber alimento. Ao escolher o vermelho, seu companheiro recebia o alimento, já na escolha do verde os dois recebiam o alimento. Depois de algumas tentativas, os chimpanzés associaram que para se alimentar, tinham que escolher a opção que beneficiasse os dois, como forma de companheirismos para atingir um objetivo, mesmo que este esteja ligado ao condicionamento para receber a alimentação como algo positivo (DE WALL, 2011; RAPCHAN; NEVES, 2017).

Essa capacidade não está relacionada aos primatas apenas porque possuem cérebros grandes, pois um papagaio, o Alex, que possui o cérebro de $9 \mathrm{~g}$ (sendo o do 
ser humano com $1500 \mathrm{~g}$ ), conseguiu reproduzir diversas palavras equivalentes ao vocabulário de uma criança de dois anos, contava até seis e demonstrava objetos de diversas cores. Alex era um pássaro, não tinha neocortex, mas conseguia raciocinar (SZKLARZ, 2018).

De Wall (2011) também analisou um experimento com elefantes, em que o animal precisava entender que somente com a parceria do seu companheiro de manada conseguiriam alcançar um alimento, se não tivessem os movimentos sincronizados o teste dava errado e eles não chegavam na área da comida, então associaram que a cooperação levava ao objetivo e logo estavam realizando a atividade de forma mais rápida e eficaz (DE WALL, 2011).

Diversos documentários, reportagens, artigos, entre outros meios de divulgação científica, mostram o comportamento de animais silvestres e selvagens em relação à caça momento em que são necessárias estratégias e técnicas, realizadas para gerar alimento para o indivíduo ou o bando. Também é possível observar e identificar o modo em que se preparam para acasalar, com métodos de atração das fêmeas, seja por cor de pelagem, feromônios e danças, a necessidade de se proteger de predadores ou de alguma situação climática. Para que essas reações ocorram, o animal precisa ter passado por uma experiência que Ihe causou uma vivência para se adaptar à situação exposta e, consequentemente, gerou um tipo de memória (CLARKE et al., 2017; ANDRADE, 2018). Para conseguir elucidar melhor sobre as emoções e sentimentos, existem alguns pontos escolhidos para se analisar.

\section{CONSCIÊNCIA - SENCIÊNCIA}

A consciência tem seu significado anterior "consciente de si mesmo" e "consciente de algo" foram substituídos por "estar consciente de algo". Este é o uso transitivo da palavra e Hacker (2013) indica que se tornar e estar consciente de algo não é realizar um ato de qualquer tipo. Tornar-se consciente de algo é uma ocorrência em um determinado momento, não algo que se faz (HACKER, 2013 citado por DU TOIT, 2015).

Existem dois tipos de consciência: a transitiva e a intransitiva, é estar desperto e não adormecido, mas não é equivalente a pensar. Tornar-se consciente não é prestar atenção ou focar em algo, tampouco pensar, refletir, decidir etc. Consciência não é uma atividade, mas algo que acontece com o ser, esta é uma característica dos animais, sendo consequência da sensação e percepção de prazer, dor, medo, fome, alegria, mas eles não têm uma vida interior de reflexão ou sentimento articulado (HACKER, 2013 citado por DU TOIT, 2015).

A senciência é a capacidade de ser afetado positiva ou negativamente e sentir as experiências que ocorrem. Não é a mera capacidade para perceber um estímulo ou reagir a uma dada ação, como no caso de uma máquina que desempenha certas funções quando um botão é pressionado, ser senciente é receber e reagir a um estímulo de forma consciente, experimentando-o a partir de dentro, é possível entender que por conseguirem passar por determinadas experiências como caça, perda de membros do bando, fome, frio, prazer ou dor, os animais não - humanos também têm a capacidade de sentir, de forma consciente, o que está acontecendo ao seu corpo e em 
seu entorno. Portanto, conseguem responder aos estímulos bioquímicos, físicos e comportamentais (CLARKE et al., 2017; ANDRADE, 2018; ÉTICA ANIMAL, 2020).

Como reconhecimento do que se passa em seu entorno, alguns estudos estabelecem que animais também conseguem entender que eles são eles quando colocados em frente à um espelho, é o caso dos chimpanzés, famosos e revolucionários estudos da primatóloga Jane Goodall, e dos golfinhos, conferidos por Loius Helman (SZKLARZ, 2018). Além disso, chimpanzés também demonstram comportamento de vergonha, cobrindo o rosto quando fazem algo que não deviam e egoísmo, escondendo algum alimento que não quer compartilhar com seus irmãos de bando (SZKLARZ, 2018).

Já o choro de um gato com fome é um sinal evidente de um hábito adaptado, isso foi descrito por Karen McComb, da Universidade de Sussex, na Inglaterra, que relata que alguns gatos vocalizam uma súplica de alta frequência similar ao choro de um bebê, é uma forma de alerta de urgência no cérebro humano, que é adaptado para atender aos sinais da prole. O resultado disto é que os humanos entendem que devem atender aos chamados dos gatos e, automaticamente, os alimenta (SZKLARZ, 2018). Comportamento este que tem relação ao princípio de hábito como adaptação que os gatos domésticos desenvolveram para garantir alimentação, explicado por Charles Darwin em "A expressão das emoções do homem e dos animais" (DARWIN, 2009) [1872].

O movimento pela desobjetificação animal, busca reconhecer animais como seres sencientes, dotados biologicamente de emoção e capazes de ter algum nível de sofrimento. Anteriormente, no Brasil, o artigo 82 do Código Civil, os caracterizava como objetos, entretanto, o PLC 27/18 estabelece que os animais passam a ter natureza jurídica sui generis, como sujeitos de direitos despersonificados. A partir dessa diretriz, eles passaram a ser reconhecidos como seres sencientes, ou seja, dotados de natureza biológica e emocional e passíveis de sofrimento (JURISTAS, 2019), o que já ocorre na Áustria, desde 1988; Holanda, desde 2011; França, desde 2015, e, em Portugal, (2017).

Após a aprovação, o artigo passa a ser utilizado juntamente com a Lei 9.605/98 de Crimes Ambientais, artigo 32, que criminaliza maus tratos a animais a uma pena de três meses a um ano e multa, podendo ser agravado em casos de morte do animal. Observa-se que essa lei não é respeitada, muitos animais ainda são vistos sofrendo por maus tratos, constantemente, por falta de sensibilização de algumas pessoas.

Após muitas manifestações de ativistas e simpatizantes da causa animal em 2020, o artigo 32 da lei 9.605/98 foi alterada com a inclusão da Lei no 14.064 "Lei Sansão", que determina o aumento de pena para dois a cinco anos nos casos de maus tratos contra cães e gatos (que representam a maioria dos animais domésticos nos lares brasileiros), além da multa e proibição da guarda (BRASIL, 2020; OLIVEIRA, 2020). Percebe-se que é um avanço na causa do bem-estar animal e mesmo que ainda não inclua animais silvestres, é um passo importante que precisa de fiscalização, sensibilização e apoio da população e governantes. 


\section{COMUNICAÇÃO}

A linguagem é um conjunto de comportamentos, falado ou não. Os seres humanos são capazes de falar, escrever e utilizar gestos corporais, e ainda sim, há dificuldade de comunicação quando ocorre uma visita a algum país em que a língua local não é a língua-mãe. Mesmo assim uma comunicação é estabelecida, sempre encontrando uma maneira de que a mensagem chegue ao destinatário. O mesmo pode acontecer na comunicação humano-cão, por exemplo (NEVES, 2020).

Peter Singer (1993) descreveu o termo "Especifismo" (criado por Richard Ryder, em 1970) como o tratamento discriminatório dos seres humanos em relação aos seres não humanos. (SINGER, 1993 citado por TONETTO, 2004; PAZÓ; CARPES, 2015; BAPSTISTELLA; ABONIZIO, 2017). Claramente, esse conceito baseia-se no préjulgamento que os seres humanos têm por não estabelecer uma linguagem direta e clara com os demais seres, especialmente, pelo fato de haver comunicação clara e direta com outros humanos e não tão claramente com os demais seres de outras espécies e desta forma, não é possível saber o que é "ser" um indivíduo de outra espécie (DU TOIT, 2015; BAPSTISTELLA; ABONIZIO, 2017).

Os conceitos que abordam que os animais não são conscientes porque não se expressam, estão restritos em linguagem falada, pois o ser humano desenvolveu, ao longo da sua evolução, uma caixa vocal. Porém, é possível observar, com algumas pesquisas disponíveis que os cetáceos, por exemplo, possuem uma vocalidade ao comunicar-se com demais membros da sua sociedade. Golfinhos são mamíferos aquáticos, da classe cetácea, subordem odontocetos, com muitas capacidades, dentre estas, caça, reprodução, comunicação, relacionamento com demais indivíduos, transferência de cultura e ecolocalização (ou localização pelo eco, que permite que esses mamíferos tenham percepção tridimensional do meio, podendo localizar precisamente as presas e perceber a distância e a característica física dos objetos) (BENEDITTO et al., 2010 citado por STEFANELI; MONTANHA, 2011).

Quanto à comunicação, os golfinhos conseguem fazer 30 tipos de sons diferentes, entre eles um assobio individualizado que, embora lembre o da sua mãe, é exclusivo de cada animal. Outros sons incluem estalidos furiosos emitidos entre os machos agressivos, e "risadinhas" íntimas trocadas quando os machos e as fêmeas se acariciam. Os estalidos são de até 700 estalidos por segundo, sendo rápido demais para a capacidade analítica do ouvido e cérebro humano (BIRKHEAD et al., 1998 citado por STEFANELI; MONTANHA, 2011). Esse tipo de comunicação foi descrito por pesquisadores que estudam Bioacústica, dispondo de equipamentos específicos para a captação de diferentes tipos de sons.

O psicólogo Louis Herman, em 2002 na Universidade do Havaí, EUA, trabalhou com um experimento com golfinhos, bem similar aos usados em adestramento de cachorros (caso da Chaser, uma border collie que aprendeu o nome de mais de dois mil objetos). Utilizando um teclado subaquático, adaptado com diversos símbolos, os animais precisavam pressionar o símbolo específico para solicitar água, alimento, brinquedo, entre outros, quando pressionavam o teclado, um som de computador produzia frases e eles entendiam os comandos como bater na bola do lado esquerdo ou direito ou levar uma prancha para alguém na água, estabelecendo um tipo de comunicação entre cetáceos e humanos (SZKLARZ, 2018). 
$\mathrm{Na}$ teoria modular da mente, de Steven Mithen, humanos possuem quatro módulos relacionados à inteligência natural, social, comunicativa e técnica. Para Mithen, chimpanzés possuem os mesmos módulos de inteligência. Contudo, diferentemente dos chimpanzés, os humanos apresentam uma "fluidez cognitiva", ou seja, os conteúdos cognitivos de cada módulo de inteligência podem se deslocar e se unir (MITHEN, 2002; RAPCHAN; NEVES, 2017). Entretanto, isso não impede o chimpanzé, que é um animal selvagem, demonstrar alta capacidade de estabelecer comunicação com humanos já que em 1971, o chimpanzé Washoe, resgatado de um dos projetos da NASA, cresceu sem se identificar como chimpanzé selvagem, aprendeu 150 palavras de Ameslan (comumente utilizado por surdos-mudos) e em um projeto similar, o bonobo, Kanzi, conseguiu aprender e se comunicar com mais de 200 símbolos de lexiagramas. Shipman relata que Kanzi "podia formar frases primitivas" (SHIPMAN, 2011 citado por DU TOIT, 2015).

Outra dúvida que ocorre acerca da comparação de sentimentos e expressões dos animais em relação aos seres humanos é a expressão da personalidade "carinhoso", "curioso", "raivoso", "calmo", "tímidos", "ousados" e como eles reagem ao ambiente. Santa'anna e Valente (2016), explicaram que existem vários testes que podem ser utilizados com a finalidade de expressar a personalidade individual (SANTA'ANNA; VALENTE, 2016).

Alguns desses testes são: Teste do novo objeto, em que é inserido um objeto que os animais nunca tiveram contato, resultou em indivíduos que têm temperamento mais 'ousado' e 'curioso', interagiram com o objeto. Já os mais 'medrosos' e 'tímidos' mantinham certa distância ou fugiam; Teste de campo aberto, deixando o animal sozinho por um período curto de tempo para identificar se ele apresenta "medo" ou explora o ambiente; Paradigma resiste-intruso, inserindo um animal da mesma espécie, mas desconhecido para verificar se ele imediatamente agredirá o novato ou se buscará apenas reconhecê-lo, revelando uma tendência à agressividade (marcação de território) ou receptividade; Teste de distância de fuga, um observador, geralmente não familiar ao animal, tenta aproximar-se de cada indivíduo, invadindo sua zona de fuga, as reações pode ser: aproximar-se do observador (animal muito dócil), esquivar-se (animal amedrontado) ou até mesmo tentar atacar 0 avaliador (animal agressivo) (SANTA'ANNA; VALENTE, 2016).

Nesse mesmo estudo, também foi relatado que a personalidade pode ser diferenciada dependendo do funcionamento de cada organismo, podendo variar de indivíduo para indivíduo, por determinados mecanismos biológicos como eriçamento dos pelos, pupila dilatada, urinar e defecar, entre outras. O comportamento "temperamental" de cada indivíduo também pode ser reflexo da genética ou do ambiente em que ele se desenvolveu. Por exemplo, os animais silvestres podem apresentar comportamentos mais agressivos por um mecanismo de defesa e os animais domésticos, por sua vez, podem apresentar uma personalidade mais aproximada dos seres humanos por estar no convívio social humano há milhares de anos, foi o que aconteceu com os cachorros, descendentes dos lobos cinzas, mas que se adaptaram ao meio humano devido à facilidade de alimentação e conforto (SANTA'ANNA; VALENTE, 2016). 


\section{GENTILEZA, EMPATIA}

Segundo estudos realizados por Michael Poulin na Universidade de Búfalo nos EUA, concluiu que existem indivíduos que têm maior predisposição à gentileza devido a presença de receptores dos hormônios da oxitocina e vasopressina. Estes hormônios promovem o comportamento materno, demonstrando maior sociabilização (POULIN; HOLMAN, 2013, BORDA, 2016). Essas emoções positivas têm sido associadas a processos adaptativos que elevam a saúde psicológica e aumenta os níveis de felicidade (GRUBER et al., 2013; BORDA, 2016). Tanto animais quanto humanos respondem a esse tipo de estímulo, o que induz, por exemplo, efeitos anti-estresse (por exemplo, diminuição dos níveis de cortisol e pressão arterial) (UVNÄS-MOBERG, 1998; PETERSSON et al., 2017).

A produção de hormônios como oxitocina e vasopresina são estimulados pela generosidade e confiança. Segundo os estudos do Professor da Universidade Claremont, na Califórnia, Paul Zak, também conhecido como "Dr. Love", em seu livro "A Molécula da Moralidade", e abordado por Charlotte Borda (BORDA, 2016).

Maria Petersson e colaboradores, em 2017 analisaram os níveis de ocitocina e cortisol de cachorros e seus donos durante determinadas interações que eles tiveram. Durante o experimento, foram coletadas amostras de sangue para contabilizar os níveis hormonais nos tempos $0,1,3,5,10,15,30$ e 60 minutos e nesse período os tutores deveriam interagir com os cães somente nos primeiros três minutos, mas ocorreram algumas interações aleatórias durante os minutos seguintes (PETERSSON et al., 2017).

Segundo Petersson et al. (2017), principal autora do estudo em questão, com base em dados anteriores do experimento apresentado neste manuscrito: "mostramos que a interação entre tutores e seus cães resulta em níveis crescentes de ocitocina nos tutores e cães, enquanto os níveis de cortisol diminuem nos tutores, mas aumentam nos cães" (HANDLIN et al., 2011; PETERSSON et al., 2017). Além disso, "os níveis de ocitocina dos tutores e dos cães estão intimamente relacionados" (HANDLIN et al., 2012; PETERSSON et al., 2017).

Como conclusão, os autores descreveram: "Também demonstramos que altos níveis de ocitocina em tutores e cães, e baixos níveis de cortisol nos tutores, estão associados à descrição do tutor da relação tutor-cachorro como agradável, interativa e associada a menos problemas" (HANDLIN et al., 2012; PETERSSON et al., 2017). Por fim, foram identificados que os níveis de ocitocina e cortisol, tanto em cães quanto em seus tutores, estão associados à interação entre os tutores e seus cães. Estudos como esses podem explicar o compartilhamento de sentimentos que os tutores relatam em ter com os seus animais de estimação. Anteriormente, subjetivo e inexplicável, hoje tangível em processos moleculares.

Exemplos bem claros dos benefícios à interação com animais domésticos para os seres humanos são: cachorros e gatos utilizados para melhorar a estadia de enfermos em hospitais, o que culminou na TAA (Terapia Assistida por Animais), PL 4455/12 em tramitação (MIRANDA, 2013; XAVIER, 2019). Eles não possuem vínculo com aquelas pessoas, mas desempenham uma gentil função de estar com elas e por um breve momento acalentar as suas dores. "A visita dos animais propicia momentos felizes às crianças, que se esquecem dos traumas da hospitalização por algum tempo, guardando 
em suas memórias lembranças boas da convivência com eles. A companhia dos animais pode afastar a dor, a tristeza e o medo, mesmo que temporariamente, preenchendo o vazio da solidão. Também favorece o desenvolvimento de sentimentos positivos, a troca de afeto e a sensação de conforto e bem-estar, à medida que propicia o estabelecimento de um vínculo com as pessoas" (VACCARI; ALMEIDA, 2007).

Alguns estudos, como o da Universidade de Kyushu, no Japão, mostram que cães conseguem identificar quando humanos estão com determinados tipos de câncer. "A pesquisa utilizou 200 voluntários, dos quais alguns eram saudáveis, outros tinham câncer de pulmão ou doença pulmonar obstrutiva crônica. A respiração de cada um deles foi analisada pelos animais treinados, que conseguiram identificar 71 pessoas com câncer de pulmão de um total de 100 possíveis. Eles também mostraram que outras 372 amostras (de um total de 400) não apresentavam tumores" (UFG, 2020).

O reconhecimento dos sentimentos e a prática dos valores permitem produzir emoções positivas para aumentar a felicidade e a saúde psicológica (GRUBER et al., 2013; BORDA, 2016), mediante atitudes como gentileza, amabilidade, respeito, entre outras. Todos esses princípios permitem o aumento de hormônios da felicidade (HAASE et al., 2012; BORDA, 2016).

Além de gatos e cachorros, já existem estudos que relatam que golfinhos têm interagido com crianças, autistas, deficientes e depressivos e que eles causam melhoras significativas na qualidade de vida dessas pessoas. "Em alguns lugares ao longo da costa da Inglaterra e Irlanda, golfinhos selvagens fixaram residência em bancos de areia e nadam e brincam com os homens, saltando perto dos barcos e cutucando nadadores" (BIRKHEAD et al., 1998 citado por STEFANELLI; MONTANHA, 2011). Acredita-se que esse tipo de interação de humanos com animais de estimação ou silvestres como os golfinhos, pode produzir interferon - uma proteína que alimenta o sistema imunológico, além de estimular a produção de analgésicos, como endorfina.

Outra curiosidade essa relação humano-animal é que ao dar à luz, os cetáceos empurram o bebê golfinho para a superfície para ajudá-lo a respirar. O que já foi observado em interações entre cetáceos e seres humanos se afogando. (BIRKHEAD et al., 1998 citado por STEFANELI; MONTANHA, 2011). Outros golfinhos que vivem em estuários, possuem um relacionamento de interação com os pescadores para sinalizar que está na temporada de peixes. Os pescadores lançam as redes e os peixes não emalhados são afugentados, logo, os golfinhos também podem aproveitar do alimento, fazendo um trabalho em conjunto (BENEDITTO et al., 2010 citado por STEFANELI; MONTANHA, 2011).

Cetáceos já demonstraram que possuem noção da diferenciação de si próprio e das necessidades do outro quando estão em angústia e decidem agir de forma para aliviar seu sofrimento, como as baleias jubarte (Megaptera novaeangliae) que já demonstraram comportamento empático, quando foram observadas realizando comportamentos agressivos, para defender outros indivíduos como peixes e mamíferos marinhos pequenos, contra os ataques de pods de orcas (Orcinus orca) mesmo que esse gasto energético não causasse benefício direto para elas (PITMAN et al., 2016; PÉREZ-MARINQUE; GOMILA, 2018). Esses comportamentos sugerem níveis de entendimento de apuros, gerando empatia e cooperação para se livrarem de situações de ataques. 


\section{SOFRIMENTO E LUTO}

Quais são os meios para medir se um animal está em sofrimento ou não já que não é possível simplesmente perguntar. Entretanto, se sabe que os animais também desenvolveram expressões para emitir seus sentimentos e emoções, é possível identificar algumas situações no cotidiano. Em eventos como a vaquejada, é comum e "cultural" que os vaqueiros (montados a cavalos) tenham que derrubar e puxar o boi pela cauda. Essa prática pode causar diversos danos ao animal, como fraturas nas patas, traumatismos e deslocamento da articulação da cauda, precisando realizar a amputação em alguns casos. Entretanto, a cauda é uma continuação da coluna vertebral do animal e que possui uma série de terminações nervosas. (OLIVEIRA, 2017).

O mesmo vem ocorrendo em parques aquáticos, golfinhos ficam confinados durante anos para servirem de entretenimento para atividades dos seres humanos. Eles são separados dos membros da sua comunidade e tem grandes problemas de interação com indivíduos de outras comunidades. Podem ter impactos no comportamento como a vocalização, movimentos repetitivos e automutilação. As interações dos animais em cativeiro com seres humanos, sem medidas enquadradas nas Cinco Liberdades, podem acarretar em transmissão de doenças e a ineficácia da recuperação do comportamento silvestre quando devolvidos à natureza, conforme relatório da Word Animal Protection, em 2019, apresentado na ITB Berlim - uma das maiores feiras de turismo do mundo (WORD ANIMAL PROTECTION, 2019).

$\mathrm{E}$ por fim, o sentimento de luto. A todo momento, é possível identificar comportamentos diferenciados de animais de estimação que estiveram ao lado dos seus tutores quando esses estavam prestes a falecer ou já haviam falecido. Casos famosos de cães, como o Hachi-ko da raça Akita, década de 1920 no Japão, que esperava seu tutor, já falecido, em uma estação de trem, hábito que faziam quando o tutor estava vivo. Esses animais criam laços emocionais e de rotina com seus tutores, sofrem com suas perdas, demonstram sinais de que estão tendo algum tipo de sentimento similar ao estado de luto (FERREIRA, 2018).

Ao escrever para o site Greenme, Gisella Meneguelli (2016) aborda um estudo realizado pela Universidade de Milano-Bicocca, na Itália, em que os cetáceos ficam tristes com as mortes de seus parentes, devido ao forte vínculo que estabelecem durante a vida e que esses animais estão de luto porque sentem dor e estresse por saberem que há algo errado (MENEGUELLI, 2016).

A Orca conhecida como $L 72$ perdeu seu filhote recém-nascido e foi destaque mundial, pois nadou por 17 dias com seu filhote na boca para mantê-lo à superfície e se manteve próximo à praia alguns dias após os pesquisadores recolherem a carcaça do seu possível filhote para o descarte correto. Seu comportamento foi associado como resistência em "deixar seu filhote partir" (MENEGUELLI, 2016; REGGENTE et.al., 2016; BEARZI et al. 2018). Outros casos também já foram observados com cetáceos como a tentativa de reanimação do indivíduo morto, quando o indivíduo fêmea veio a óbito e o companheiro de bando tentava empurrar seu corpo para baixo d'água na tentativa de vê-la nadar novamente (BEARZI et al. 2018)

O luto também acomete outros animais como elefantes, girafas e chimpanzés, que produzem comportamentos como se lamentassem a morte dos seus parentes mais 
próximos. Estes comportamentos são retratados no livro "O que sentem os animais?", de Barbara King, e é possível destacar que "os animais sofrem de angústia emocional associada à perturbação do comportamento usual. Esta autora dá como exemplo o elefante, que retorna várias vezes ao local onde um companheiro foi morto para visitálo", como o comportamento humano em visitar entes que já se foram e possuem lápides em cemitérios (MENEGUELLI, 2016).

\section{CONSIDERAÇÕES FINAIS}

Os resultados desse trabalho emergem um assunto extremamente importante: Os animais não-humanos têm a capacidade de sentir emoções iguais ou similares às dos seres humanos? A partir de estudos como esse, é possível entrar em quesitos éticos de como os seres humanos cuidam e interagem com os animais, o que é possível fazer para aumentar o seu bem-estar e como os humanos podem ser melhores na interação com os seres de outras espécies, por meio de como ocorre a comunicação interespécie. Talvez haja uma sensibilização acerca de como as espécies animais vêm entrando em extinção pelas ações antrópicas e os impactos destes comportamentos possam ser minimizados.

No desenvolvimento deste trabalho, foi relatado que: animais não-humanos já estabeleceram demonstração de sensibilidades à dor, fome, frio, empatia, luto entre outros. Assim como, manifestaram aprendizado em diversos tipos de comunicação e de linguística, promovendo possível interação e entendimento com os seres humanos, o que só reforça a capacidade de senciência, cognição e interação social nos animais silvestres, selvagens ou domésticos, além da capacidade de sentir e produzir emoções e da abrangência para uma inteligência similar à humana, mas que funciona de outras formas e outros mecanismos.

Abordar esse estudo nos coloca à frente de questões como proteção e conservação animal. Além de leis mais rígidas em questão de maus tratos a animais e possíveis alterações e proibições na maneira como fazemos o manejo e uso de alguns deles para serviços alimentícios, cosméticos, farmacológicos e ecossistêmicos para os seres humanos.

\section{REFERÊNCIAS}

ANDRADE, M. P. Sentimentos e emoções dos animais: somos tão diferentes assim?. Universidade Federal do ABC Divulga Ciência, v.1, n.3, p.2, 2018. Disponível em: https://proec.ufabc.edu.br/ufabcdivulgaciencia/2018/09/21/sentimentos-e-emocoes-dosanimais-somos-tao-diferentes-assim. Acesso em: 29/08/2020.

BAPTISTELLA, E; ABONIZIO, J. O peso dos animais nas urnas: uma reflexão sobre o papel dos animais na política contemporânea. Revista Brasileira de Ciência Política, Brasília , n. 22, p. 329-372. 2017 . Disponível em: http://www.scielo.br/scielo.php?script=sci_arttext\&pid=S0103-

33522017000100329\&Ing=pt\&nrm=iso. Doi: $\quad$ https://doi.org/10 https://doi.org/10.5007/1807-1384.2016v13n2p76.1590/0103-335220172209. Acesso em: 29/08/2020. 
BAPTISTELLA, E; ABONIZIO, J. Entre espécies e ciências: uma reflexão sobre a utilização de argumentos científicos para legitimação da causa animal. Interthesis., v. $13 \quad$ n. $2,2016.2$ Disponível em: https://periodicos.ufsc.br/index.php/interthesis/article/view/1807-1384.2016v13n2p76. Doi: https://doi.org/10.5007/1807-1384.2016v13n2p76. Acesso em: 29/08/2020.

BATESON, M. Cumulative stress in research animals: Telomere attrition as a biomarker in a welfare context? BioEssays. v. 38, n. 2, 2015. Disponível em: https://onlinelibrary.wiley.com/doi/full/10.1002/bies.201500127. https://doi.org/10.1002/bies.201500127. Acesso em: 12/07/2020.

BEARZI, G; KEREM, D; FUREY, N. B; PITMAN, R. L; RENDELL, L; REEVES, R. R. Whale and dolphin behavioural responses to dead conspecifics. Elsevier Zoology. v. 128, p. 1-15. Disponível em: https://pubmed.ncbi.nlm.nih.gov/29801996. doi: 10.1016/j.zool.2018.05.003. Acesso em: 12/11/2020.

BEKOFF, M. Vida Emocional dos Animais: Alegria, Tristeza E Empatia Nos Animais. São Paulo: Cultrix, 2010.

BORDA, C C: Gentileza, o poder do sucesso. Revista Compartilhe Docência, v.1, n.2, 2016.

Disponível em:

https://revistaseletronicas.fmu.br/index.php/CompartilheDocencia/article/view/1159.

Acesso em: 13/11/2020.

BRASIL. Lei no 14.064, de 29 de setembro de 2020. Altera a Lei oㅜ 9.605, de 12 de fevereiro de 1998, para aumentar as penas cominadas ao crime de maus-tratos aos animais quando se tratar de cão ou gato. Disponível em: https://www.in.gov.br/web/dou/-/lei-n-14.064-de-29-de-setembro-de-2020-280244746. Acesso em: 21/12/2020.

CABRAL, L. M. DE S; SILVA, T. T. DE A. O não humano no agrupamento familiar: novo conceito de guarda compartilhada na família multiespécie. Repositório Institucional Universidade Católica de Salvador. 2019. Disponível em: http://ri.ucsal.br:8080/jspui/handle/prefix/989. Acesso em Acesso em: 10/12/2020.

CAPUCCHIO, M. T; COLOMBINO, E; TARANTOLA, M; BIAGINI, D; ALBORALI, L. G; MAISANO, A. M; SCALI, F; et al. The Disturbed Habitat and Its Effects on the Animal Population. Animal Behaviour [Habitats of the word].2019. Disponível em: https://www.intechopen.com/books/habitats-of-the-world-biodiversity-and-threats/thedisturbed-habitat-and-its-effects-on-the-animal-population. doi:10.5772/intechopen.84872. Acesso em: 10/12/2020. 
CLARKE, N; MAIN, D. C. J; PAUL, E. S. Students' beliefs in animal sentience: no decline across veterinary education. Veterinary Record. v.180, p. 378. 2017. Disponível em: https://veterinaryrecord.bmj.com/content/180/15/378.2. doi: http://dx.doi.org/10.1136/vr.104165. Acesso em: 12/07/2020.

DARWIN, C. A expressão das emoções no homem e nos animais. São Paulo: Companhia das Letras, 2009.(Trabalho original publicado em 1872).

DAMÁSIO, A. O Mistério da Consciência: do corpo e das emoções ao conhecimento de si. São Paulo: Companhia das Letras, 2015.

DAMÁSIO, A. A estranha ordem das coisas: As origens biológicas dos sentimentos e da cultura. São Paulo: Companhia das Letras, 2018.

DEAN, W; MORGAN R. F. In defense of the concept of biological aging measurement current status. Elsevier Archives of Gerontology and Geriatrics, v.7, p. 191-210. 1988. Disponível em: https://pubmed.ncbi.nlm.nih.gov/3052338. Doi: 10.1016/01674943(88)90002-7. Acesso em: 2/09/2020.

DE WAAL, F. Comportamento moral em animais. TEDXPeachtree. 2011. Disponível em: https://www.ted.com/talks/frans_de_waal_do_animals_have_moral?language=pt-br. Acesso em: 24/02/2020.

DU TOIT, C W.. Pursuing an understanding of animal consciousness: Implications for animal morality and a creaturely theology. Verbum Ecclesia, v. 36, n. 3, p. 1-10, 2015. Disponível em: http://www.scielo.org.za/scielo.php?script=sci_arttext\&pid=S207477052015000300006\&lng=en\&nrm=iso. doi:http://dx.doi.org/10.4102/ve.v36i3.1442. Acesso em: 24/02/2020.

ÉTICA ANIMAL. Introdução a senciência. Disponível em: https://www.animalethics.org/senciencia-secao/introducao-a-senciencia/senciencia-animal/> Acesso em: 06/03/2020.

FERREIRA, N. A história de Hachiko, o cachorro fiel. Perito Animal. Disponível em: https://www.peritoanimal.com.br/a-historia-de-hachiko-o-cachorro-fiel-21454.html.

Acesso em: 06/03/2020.

GARMENDIA, G. T. De Mello, M. (Ed.): Human-Animal Studies: A Bibliography. Discusiones Filosóficas. v. 16, n. 27, p. 195-202. 2015. Disponível em: http://www.scielo.org.co/scielo.php?script=sci_arttext\&pid=S0124-

$61272015000200012 \& \operatorname{lng}=$ en\&nrm=iso.

Doi:

http://dx.doi.org/10.17151/difil.2015.16.27.12. Acesso em: 10/12/2020. 
GIUMELLI, R. D; SANTOS, M. C. P. Convivência com animais de estimação: um estudo fenomenológico. Revista Abordagem Gestáltica. v. 22, n. 1, p. 49-58. 2016. Disponível em: http://pepsic.bvsalud.org/scielo.php?script=sci_arttext\&pid=S1809$68672016000100007 \&$ lng=pt\&nrm=iso. Acesso em: 11/12/2020.

GRUBER, J.1; KOGAN, A; QUOIDBACH, J; MAUSS, I. B. Happiness is best kept stable: positive emotion variability is associated with poorer psychological health. American Psychological Association. v. 13, n. 1, p. 1-6. 2013. Disponível em: https://pubmed.ncbi.nlm.nih.gov/23163709. doi: 10.1037 / a0030262. Acesso em: $10 / 12 / 2020$

HAASE, C. M; POULIN, M. J; HECKHAUSEN, J. Happiness as a motivator: Positive high-arousal affect enhances primary control striving. Personality and Social Psychology Bulletin. v. 38,p. 1093 - 1104. 2012. Disponível em: https://pubmed.ncbi.nlm.nih.gov/22569224. doi: 10.1177/0146167212444906. Acesso em: 06/03/2020.

HANDLIN, L.; HYDBRING-SANDBERG, E; NILSSON, A; EJDEBÄCK, M; JANSSON, A; UVNÄS-MOBERG, K. Short-term interaction between dogs and their owners - effects on oxytocin, cortisol, insulin and heart rate - an exploratory study. Anthrozoos. n. 24, p. 301-315. $2011 . \quad$ Disponível em: https://www.tandfonline.com/doi/abs/10.2752/175303711X13045914865385> doi: 10.2752/175303711X13045914865385. Acesso em: 06/03/2020.

HANDLIN L., HYDBRING-SANDBERG E., NILSSON A., EJDEBÄCK M., UVNÄSMOBERG K. (2012). Associations between the psychological characteristics of the human-dog relationship and oxytocin and cortisol levels. Anthrozoos. v. 25, n. 2, p. 215-228. $2012 . \quad$ Disponível em: https://www.tandfonline.com/doi/abs/10.2752/175303712x13316289505468. doi:10.2752/175303712X13316289505468. Acesso em: 06/03/2020.

INSTITUTO PET BRASIL. Censo Pet: 139,3 milhões de animais de estimação no Brasil. Disponível em: http://institutopetbrasil.com/imprensa/censo-pet-1393-milhoesde-animais-de-estimacao-no-brasil. Acesso em: 11/12/2020.

JURISTAS. PL prevê mudança da natureza jurídica para animais. (2019). Disponível em: https://juristas.com.br/2019/08/09/projeto-de-lei-aprovado-estabelece-que-animalnao-e-coisa/. Acesso em: 26/05/2020.

LYDDY, F. Lateral bias in chimpanzee expressions of facial emotion. Trends in Cognitive Sciences. v. 6, n. 9, p. 369-371, 2002. Disponível em: 
https://europepmc.org/article/med/12200173. doi: 10.1016 / s1364-6613 (02) 01972-1. Acesso em: 06/03/2020.

NEVES, F. Tipos de linguagem: linguagem verbal e não-verbal. Norma culta Língua Portuguesa e bom Português. Disponível em: https://www.normaculta.com.br/tipos-delinguagem-linguagem-verbal-e-nao-verbal. Acesso em: 11/12/2020.

$\begin{array}{llll}\begin{array}{l}\text { MENEGUELLI, G. Estudo afirma que golfinhos e baleias sentem pela perda de } \\ \text { parentes }\end{array} & \text { próximos. } & (2016) . & \text { Disponível }\end{array}$ https://www.greenmebrasil.com/informarse/animais/3788-golfinhos-baleiasluto/\#: :text=Estudo\%20afirma\%20que\%20golfinhos\%20e\%20baleias\%20sentem $\% 20 p$ ela\%20perda\%20de\%20parentes\%20pr\%C3\%B3ximos,-

Gisella\%20Meneguelli\&text=J\%C3\%A1\%20foram\%20vistos\%20sete\%20esp\%C3\%A9ci es,esse\%20fen\%C3\%B4meno\%20chama\%2Dse\%20luto. Acesso em: 06/06/2020.

MELLOR, D.J. Moving beyond the "Five Freedoms" by Updating the "Five Provisions" and Introducing Aligned "Animal Welfare Aims". Animals; an open acess jornal from MDPI. v.6, n. 10, p. 59. 2016. Disponível em: https://www.ncbi.nlm.nih.gov/pmc/articles/PMC5082305/.

doi: 10.3390 / ani6100059. Acesso em: 06/03/2020.

MIRANDA, T: Hospitais do SUS poderão oferecer terapia com animais. Disponível em: $\quad$ https://www.camara,leg.br/noticias/393974-hospitais-do-sus-poderao-oferecerterapia-com-animais. Acesso em: 06/03/2020.

MITHEN, S. A pré-história da mente. Educar em revista. 2003 (Trabalho original publicado em 2002). Disponível em: https://www.researchgate.net/publication/277041008_MITHEN_S_A_pre-

historia_da_mente_-_uma_busca_das_origens_da_arte_da_religiao_e_da_ciencia. Acesso em: 06/03/2020.

NAVES, B. T. DE O; VARELA, A. M. A. R. Família, família, cachorro, gato, galinha: a família multiespécie e a guarda compartilhada dos animais de estimação, após a ruptura do vínculo. Revista Internacional Consinter de Direito, n. 6, p. 409. 2018. Disponível em: https://revistaconsinter.com/revistas/ano-iv-numero-vi/direitoprivado/familia-familia-cachorro-gato-galinha-a-familia-multiespecie-e-a-guardacompartilhada-dos-animais-de-estimacao-apos-a-ruptura-do-vinculo-conjugal-no-brasil/. doi: 10.19135/revista.consinter.00006.18. Acesso em: 10/12/2020.

OLIVEIRA, M. V. Análise jurídica da vaquejada em face do conflito entre o direito fundamental à cultura e o dever de proteção ambiental. Universidade de Brasília. 2017. 
https://bdm.unb.br/bitstream/10483/18222/1/2017_MarcusViniciusdeOliveira.pdf . Acesso em: 08/12/2020.

OLIVEIRA, Y D. "Lei Sansão": saiba mais sobre a Lei no $14.064 / 2020$, que aumenta a pena para maus-tratos a cães e gatos. Jusbrasil. (2020). Disponível em: https://yagodiasdeoliveira.jusbrasil.com.br/noticias/938088093/lei-sansao-saiba-maissobre-a-lei-n-14064-2020-que-aumenta-a-pena-para-maus-tratos-a-caes-e-gatos. Acesso em 21/12/2020.

PAZÓ, C.G; CARPES, L.F. A interferência do especismo no reconhecimento como sujeitos de direito dos animais não-humanos. Planeta Amazônia: Revista Internacional de Direito Ambiental e Políticas Públicas, n. 6, p. 13-29, 2014. Disponível em: https://periodicos.unifap.br/index.php/planeta/article/view/1192\#: :text=Alguns\%20seres \%20humanos\%20apresentam\%20limita\%C3\%A7\%C3\%B5es,entre\%20diferentes\%20e sp\%C3\%A9cies\%20de\%20animais.\&text=Relativamente\%20capazes\%20e\%20absolut amente\%20incapazes,de\%20ser\%20sujeitos\%20de\%20direito. Acesso em: 10/12/2020.

PEREZ-MANRIQUE, A; GOMILA A. The comparative study of empathy: sympathetic concern and empathic perspective-taking in non-human animals. Biological Reviews. n. 93, p. 248-269. 2018. Disponível em: . Doi: 10.1111/brv.12342. Acesso em: 06/10/2020.

PETERSSON, M; UVNÄS-MOBERG, K; NILSSON, A; GUSTAFSON, L; HYDBRINGSANDBERG, E; HANDLIN, L. Níveis de ocitocina e cortisol em donos de cães e seus cães estão associados a padrões comportamentais: um estudo exploratório. NCBI, Frontier in Psychology, v. 8, p.1796. 2017. Disponível em: https://www.ncbi.nlm.nih.gov/pmc/articles/PMC5645535/> doi: 10.3389 fpsyg.2017.01796. Acesso em: 06/03/2020.

PICKARD, J. Review of the assessment of cumulative severity and lifetime experience in non human primates used in neuroscience research. The Animal Procedures Committee. 2013.

Disponível em: www.gov.uk/government/uploads/system/uploads/attachment_data/file/261687/cs_ nhp_review_FINAL_2013_corrected.pdf. Acesso em: 06/03/2020.

PITMAN, R. L; DEECKE, V. B; GABRIELE, C. M; SRINIVASAN, M; BLACK, N. et. al. Humpback whales interfering when mammal-eating killer whales attack other species: mobbing behavior and interspecific altruism? Marine Mammal Science. v. 33, p. 7-58. 2016. Disponível em: https://onlinelibrary.wiley.com/doi/full/10.1111/mms.12343. doi :https://doi.org/10.1111/mms.12343. Acesso em: 06/10/2020. 
PORTO, F. Qual a diferença entre emoção e sentimento? Disponível em: https://fredericoporto.com.br/qual-diferenca-entre-emocao-e-sentimento/>. Acesso em: 06/03/2020.

POULIN, M.J.1; HOLMAN, E. A. Helping hands, healthy body? Oxytocin receptor gene and prosocial behavior interact to buffer the association between stress and physical health. Elsevier. v. 63, n. 3, p 510-7. 2013. Disponível em: https://pubmed.ncbi.nlm.nih.gov/23354128/. Doi: 10.1016/j.yhbeh.2013.01.004. Acesso em: 06/03/2020.

RAPCHAN, E S; NEVES, W A. Ser ou não ser: poderia um chimpanzé fazer a pergunta de Hamlet?. Horizontes Antropológicos., Porto Alegre, v. 23, n. 48, p. 303-333, ago. 2017 . Disponível em: http://www.scielo.br/scielo.php?script=sci_arttext\&pid=S010471832017000200303\&lng=pt\&nrm=iso. doi: https://doi.org/10.1590/s010471832017000200013. Acesso em: 06/03/2020.

REGGENTE, M. A; NICOLAU, C; FREITAS, L; CAGNAZZI, D; BAIRD, R. W; GALLI, P. Nurturant behavior toward dead conspecifics in free-ranging mammals: new records for odontocetes and a general review. Jourrnal of Mammalogy. v. 97, n. 5, p. 1428-1434. 2016. Disponível em: https://academic.oup.com/jmammal/article/97/5/1428/2219069. doi: https://doi.org/10.1093/jmammal/gyw089. Acesso em: 06/10/2020.

SANTA'ANNA, A. C; VALENTE, T. da S. Personalidade em animais: o que diz a ciência?. Revista Brasileira de Zoociências - Divulgação Científica. v. 17 n. 2. 2016. Disponível em: https://periodicos.ufjf.br/index.php/zoociencias/article/view/24650. Acesso em: 06/03/2020.

STEFANELLI, J; MONTANHA, F: Estudo comportamental dos cetáceos (golfinhos) e interação destes com os humanos - revisão de literatura. 2011. Disponível em: http://faef.revista.inf.br/imagens_arquivos/arquivos_destaque/UfgTFPaV3TEMWJH_201 3-6-27-15-25-58.pdf> Acesso em: 19/05/2020.

SZKLARZ, E. Cientistas descobrem o que passa pela cabeça dos animais. Disponível em: https://super.abril.com.br/ciencia/cientistas-descobrem-o-que-passapela-cabeca-dos-animais. Acesso em: 19/05/2020.

TELES, J. C. C. A Anterioridade dos Processos Emocionais na Estruturação do Juízo Moral. Repositório Universidade Federal de Uberlândia. 2020. Disponível em: http://repositorio.ufu.br/bitstream/123456789/28874/4/AnterioridadeProcessosEmocionai s.pdf. doi: : http://doi.org/10.14393/ufu.di.2020.29. Acesso em: 06/12/2020.

THOMAS, K. O homem e o mundo natural: mudanças de atitude em relação às plantas e aos animais (1500 - 1800). São Paulo: Companhia das Letras, 2010. 
TONETTO, M. C. Do valor da vida senciente e autoconsciente. Ethic@: Revista Internacional de Filosofia da Moral. v.3, n.3, p. 207-222, Florianópolis. 2004. Disponível em: https://periodicos.ufsc.br/index.php/ethic/article/view/14907> doi: https://doi.org/10.5007/\%25x. Acesso em: 19/05/2020.

UVNÄS-MOBERG, K. Antistress pattern induced by oxytocin. News Physiology. Science. $\quad$ n. 13, p. 22-25. 1998. Disponível em: https://pubmed.ncbi.nlm.nih.gov/11390754. doi: 10.1152/physiologyonline.1998.13.1.22. Acesso em: 07/03/2020.

UFG - Universidade Federal de Goiás. Cientista investiga uso de cães para farejar câncer. Disponível em: https://petbio.icb.ufg.br/n/44508-cientista-investiga-uso-de-caespara-farejar-cancer>. Acesso em: 29/08/2020.

VACCARI, A; ALMEIDA, F. A importância da visita de animais de estimação na recuperação de crianças hospitalizadas.Biblioteca Virtual em Saúde. v. 5, p. 11-116. 2007. Disponível em:

https://pesquisa.bvsalud.org/portal/resource/pt/lil-473691. Acesso em: 06/03/2020.

XAVIER, L. Comissão aprova terapia com animais para pacientes de hospitais ligados ao SUS. 2019. Disponível em: https://www.camara.leg.br/noticias/561696comissao-aprova-terapia-com-animais-para-pacientes-de-hospitais-ligados-ao-sus.

Acesso em: 19/05/2020.

WOLRD ANIMAL PROTECTION. O problema dos animais marinhos em cativeiro. Disponível

em:https://www.worldanimalprotection.org.br/sites/default/files/media/br_files/relatorio_o _problema_dos_mamiferos_marinhos_em_cativeiro.pdf. Acesso em: 11/11/2020. 